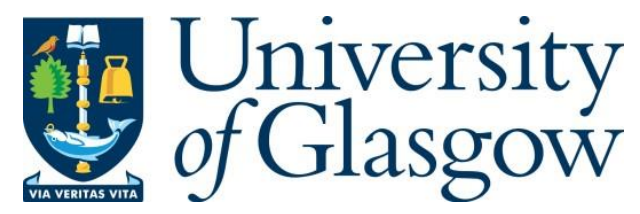

Leverick, F. (2021) Improving the management of sexual offence cases in Scotland: the Dorrian Review. Edinburgh Law Review, 25(3), pp. 385-393.

There may be differences between this version and the published version. You are advised to consult the publisher's version if you wish to cite from it.

http://eprints.gla.ac.uk/246943/

Deposited on: 15 July 2021

Enlighten - Research publications by members of the University of Glasgow http://eprints.gla.ac.uk 


\title{
Improving the Management of Sexual Offence Cases in Scotland: the Dorrian Review
}

\begin{abstract}
A. INTRODUCTION
In March 2021, the Dorrian Review into Improving the Management of Sexual Offence Cases published its report. ${ }^{1}$ The Review was commissioned by the Lord Justice-General (Lord Carloway) to "develop proposals for an improved system to deal with serious sexual offence cases". ${ }^{2}$ It comes at a time when there is increasing recognition that the prosecution of sexual offences is not all that it should be conviction rates are low and complainers report that engagement with the criminal justice process leaves them traumatised. All three UK jurisdictions have undertaken similar reviews. ${ }^{3}$

In a lengthy report that draws on academic research, the review group's own experience, and evidence from those who have experienced sexual offence prosecutions, the Review made a wide range of recommendations. This paper examines the background to the Review and outlines and assesses its main proposals.
\end{abstract}

\section{B. BACKGROUND}

The Review was undertaken against a background of low conviction rates and evidence that complainers are severely re-traumatised by their experiences of the criminal justice system. In Scotland, the conviction rate in prosecuted rape/attempted rape cases in $2019-20$ was $48 \%{ }^{4}$ The Review noted this, pointing out that conviction rates after trial in the High Court are lower for rape than for any other crime, ${ }^{5}$ but focussing on convictions at trial understates the problem. In 2018-19, 2,426 rapes/attempted rapes were reported to the police, ${ }^{6}$ but there were only 152 convictions, ${ }^{7}$ a mere six per cent of reported cases. ${ }^{8}$ The picture looks even worse when unreported incidents are considered - only half of those seeking support from Rape Crisis Scotland, for example, had reported their experience to the police. ${ }^{9}$ Other sources have put the rate of unreported sexual offences even higher - the Scottish Crime and Justice Survey 2019/20, for example, found that only 22 per cent of those who had experienced forced sexual intercourse reported it to the police. ${ }^{10}$

\footnotetext{
${ }^{1}$ Scottish Courts and Tribunals Service, Improving the Management of Sexual Offence Cases: Final Report from the Lord Justice Clerk's Review Group (2021) ("Review").

${ }^{2}$ Foreword to Review, 3.

${ }^{3}$ The Gillen Review in Northern Ireland reported in 2019: Sir John Gillen, Report into the Law and Procedures in Serious Sexual Offences in Northern Ireland (2019). In England and Wales, the Ministry of Justice's End-to-End Rape Review reported in June 2021: HM Government, The End-to-End Rape Review Report on Findings and Actions (2021).

${ }^{4}$ Scottish Government, Criminal Proceedings in Scotland, 2018-19 (2020) 16 (chart 3).

${ }^{5}$ Review, para 5.70 .

${ }^{6}$ Scottish Government, Recorded Crime in Scotland 2019-20 (2020) table 1.

${ }^{7}$ Scottish Government, Criminal Proceedings in Scotland, 2018-19 (2020) table 4(b).

${ }^{8}$ This calculation is indicative rather than exact, as figures relate to different years and not a single set of cases. That said, figures across the last few years are relatively constant, so the six per cent figure is unlikely to be wildly inaccurate.

${ }^{9}$ Rape Crisis Scotland, Annual Report for 2019-20 (2019) 35.

${ }^{10}$ Scottish Government, Scottish Crime and Justice Survey 2019/20: Associated Data Tables, table 7.26a.
} 
In terms of the complainer experience, the Review drew heavily on the report Justice Journeys, ${ }^{11}$ which presents findings from 17 in-depth interviews with sexual offence complainers. Justice Journeys makes for harrowing reading. Participants found the process of having their statement taken by police challenging and lengthy, ${ }^{12}$ had limited understanding of the legal process, ${ }^{13}$ experienced protracted delays, ${ }^{14}$ and those whose case did make it to trial found the process of giving evidence severely retraumatising. ${ }^{15}$

\section{RECOMMENDATIONS}

The Review made a wide range of recommendations - space precludes discussing them all. The focus will be on the specialist court, pre-recording of evidence, legal representation for complainers, the complainer's right to anonymity and measures aimed at preventing rape myths from influencing verdicts.

\section{A specialist court}

The Review recommended creating a national (Scottish) specialist sexual offences court. ${ }^{16}$ Its key features would be routine pre-recording of evidence for all complainers, judicial case management via ground rules hearings and trauma-informed training for all personnel (including judges and those given rights of audience). ${ }^{17}$

While this is a significant measure, the use of specialist courts in the Scottish criminal justice system is not new - a domestic abuse court has been running for several years. ${ }^{18}$ The Review was also influenced by the specialist sexual offences court in New Zealand, which has resulted in shorter case conclusion times and reduced trauma to complainers. ${ }^{19}$

The specialist court does raise certain practicalities. Indictments which feature sexual offences alongside other serious offences, such as murder/attempted murder, or where an Order for Lifelong Restriction might be under consideration, would be heard in the High Court (presided over by a judge with specialist training). ${ }^{20}$ There would be provision to transfer cases from the High Court to the specialist court and vice versa. ${ }^{21}$ The Review recommended that the sentencing powers of the new court be a maximum of 10 years imprisonment, ${ }^{22}$ although noted that this is "a sensitive issue which may require further consideration and consultation". ${ }^{23}$

\footnotetext{
${ }^{11}$ O Brooks-Hay, M Burman and L Bradley, Justice Journeys: Informing Policy and Practice Through Lived Experience of Victim-Survivors of Rape and Serious Sexual Assault (2019) ("Justice Journeys").

12 Justice Journeys, section 3.2.1.

13 Justice Journeys, section 3.3.2.

14 Justice Journeys, section 3.4.3.

15 Justice Journeys, section 3.5.3.

${ }^{16}$ Review, para 3.56 .

${ }^{17}$ Review, para 3.56.

18 Review, para 3.13.

${ }^{19}$ Review, para 3.19, citing S Allison and T Boyer, Evaluation of the Sexual Violence Court Pilot (2019).

${ }^{20}$ Review, para 3.36.

${ }^{21}$ Review, para 3.36.

${ }^{22}$ Review, para 3.44.

${ }^{23}$ Review, para 3.44.
} 


\section{Pre-recorded evidence}

The Review recommended that for cases prosecuted in the specialist court, pre-recording of the whole of the complainer's evidence, including cross-examination, should be the default way of presenting evidence. ${ }^{24}$ Any derogation from this position "should be strictly limited". ${ }^{25}$ What this means in practice is that an initial video-recorded interview with the police will act as the complainer's evidence-in-chief. Cross-examination - and any further evidence - will be secured via procedures already in use for the taking of evidence on commission. ${ }^{26}$ Ground rules hearings will allow judicial management of the themes of cross-examination and for the determination of any applications to question the complainer about their sexual history. ${ }^{27}$

The use of pre-recorded evidence, at least in the Scottish context, is not as novel as it might sound it is a continuation of ongoing work by Lord Carloway and the Scottish Courts and Tribunals Service. ${ }^{28}$ One result of this work is that a legal presumption in favour of pre-recording the evidence of child witnesses has been operating in Scotland since January $2020 .{ }^{29} \mathrm{~A}$ pilot has also been operating in three local policing divisions in respect of sexual offences since November 2019, with early indications of positive results. ${ }^{30}$

The benefits that pre-recording evidence might have for sexual offence complainers and the justice system more widely, cannot be over-stated. Involvement as a witness is concluded sooner, with the distressing wait to give evidence minimised. Cross-examination is shorter, and more reliable evidence is secured, as taking evidence as close as possible in time to the alleged incident reduces the risk of memory loss or contamination. ${ }^{31}$ It may also go some way to alleviating the re-traumatisation complainers experience when giving evidence in court.

While there might be concern that this encroaches on the accused's right to challenge the evidence, experience to date does not support this. As the Review stated, "it is quite feasible for the rights of the accused to be vindicated by sensitive cross-examination, and for that cross-examination to take place outwith the presence of the jury".$^{32}$ Conversely, there might be a concern that video testimony impacts negatively on the jury's assessment of the complainer, but here too, existing research suggests that the mode of delivery makes little, if any, difference to juror evaluations of credibility or verdicts. ${ }^{33}$ One concern is that technical difficulties - such as video quality - can have a detrimental impact on the effectiveness of this method of securing evidence. ${ }^{34}$ The Review recognised this, stating that these will need to be resolved. ${ }^{35}$

\footnotetext{
${ }^{24}$ Review, para 2.22 .

${ }^{25}$ Review, para 2.4.

${ }^{26}$ Review, para 2.13. On these procedures see s 271 l of the Criminal Procedure (Scotland) Act 1995.

${ }^{27}$ Review, para 2.17.

${ }^{28}$ See Scottish Court Service (as it then was), Evidence and Procedure Review: Report (2015); Scottish Courts and Tribunals Service, Evidence and Procedure Review: Next Steps (2016).

${ }^{29}$ See s 271BXA(3) of the Criminal Procedure (Scotland) Act 1995; High Court of Justiciary Practice Note No. 1 of 2017: Taking of Evidence of a Vulnerable Witness by a Commissioner.

${ }^{30}$ Review, para 2.12 .

${ }^{31}$ Review, para 2.5 .

32 Review, para 2.17.

${ }^{33}$ See V Munro, The Impact of the Use of Pre-Recorded Evidence on Juror Decision-Making: An Evidence Review (2018).

${ }^{34}$ Ibid, 27-28.

${ }^{35}$ Review, para 2.8 .
} 


\section{Independent legal representation for complainers}

The inappropriate admission of evidence relating to a complainer's sexual history is an issue of some concern. ${ }^{36}$ In Scotland, the law on the books, at least, is clear on this. Under section 274 of the Criminal Procedure (Scotland) Act 1995, the leading of a complainer's sexual history evidence is prohibited, subject to certain exceptions contained in section 275 . In recent years, these exceptions have been interpreted very narrowly by the courts, even to exclude evidence that the complainer has previously made a false allegation of rape, if that allegation was not related in "time, circumstances or place" 37 to the present case. But these protections have not always been well-enforced in practice ${ }^{38}$ and Keane and Convery found that applications to lead sexual history evidence often go unopposed by the Crown. ${ }^{39}$

Relying heavily on the work of Keane and Convery, ${ }^{40}$ the Review recommended that complainers should have the right to publicly funded independent legal representation (ILR) to allow them to oppose section 275 applications. ${ }^{41}$ This is a welcome move. The nature of the questioning in a section 275 application can represent "a particularly intimate, sensitive and important aspect of a complainer's private life", 42 and the complainer should be entitled to a voice. ILR will allow the prosecutor to focus on the application purely in terms of its significance for the Crown, while reassuring complainers that their views will be heard. ${ }^{43}$

\section{A legal right to anonymity for complainers}

As Tickell has pointed out, ${ }^{44}$ in Scotland there is no legal prohibition preventing the identification of the complainer in a sexual offence case - it can be done by an order of the court, but it is not automatic. There is a convention that complainers are not named, supported by the Editor's Code of the Independent Press Standards Organisation, ${ }^{45}$ but this has not always prevented complainers from being identified. ${ }^{46}$ In this, Scotland is out of step with England and Wales. ${ }^{47}$ As such, the Review recommended that "legislation is required to ensure the adequate protection of the identities of complainers making allegations of rape and sexual assault". ${ }^{48}$

\footnotetext{
${ }^{36}$ See e.g. S Cowan, The Use of Sexual History and Bad Character Evidence in Scottish Sexual Offences Trials (2020).

${ }^{37}$ M v HM Advocate (No.2) [2013] HCJAC 22 at [34] per the (then) Lord Justice-Clerk (Lord Carloway).

${ }^{38}$ See S Cowan and L Campbell, "The relevance of sexual history and vulnerability in the prosecution of sexual offences", in P Duff and PR Ferguson (eds), Scottish Criminal Evidence Law: Current Developments and Future Trends (2018) 67 at 75-82.

${ }^{39} \mathrm{E}$ Keane and T Convery, Proposal for Independent Legal Representation for Complainers Where an Application is Made to Lead Evidence of Their Sexual History or Character (2020) 13.

${ }^{40}$ Keane and Convery argue for the introduction of ILR in a similar form to that recommended by the Review: ibid at 27.

${ }^{41}$ Review, para 4.45.

42 Review, para 4.36, quoting from Keane and Convery (n 39) 17.

${ }^{43}$ Review, para 4.44.

${ }^{44}$ A Tickell, "Why don't sexual offence complainers have a right to anonymity in Scotland?" (2020) 24 Edin LR 427.

${ }^{45}$ Review, para 4.29 .

${ }^{46}$ See Tickell (n 44) 430-431.

${ }^{47}$ England and Wales is covered by the Sexual Offences (Amendment) Act 1992, which mandates anonymity in Scotland for complainants in proceedings in England and Wales but does not require anonymity in Scotland beyond this: see Tickell ( $n$ 44) at 429.

48 Review, para 4.33.
} 


\section{Measures to address juror prejudices}

There is a substantial body of evidence that jury decision making in sexual offence cases is influenced by jurors' false and prejudicial beliefs about what rape looks like and the way in which a genuine rape victim would respond to an attack - so-called 'rape myths'. ${ }^{49}$ Quantitative research demonstrates that mock jurors ${ }^{50}$ scores on rape myth acceptance scales ${ }^{51}$ are significant predictors of their verdict choices. ${ }^{52}$ Qualitative research with mock juries shows that jurors regularly express problematic beliefs during deliberations, including that an absence of extensive injuries and/or a 'failure' to shout for help is indicative of consent, women regularly make false rape allegations and even a short delay in reporting an incident is evidence that it is fabricated. ${ }^{53}$ They have also demonstrated that even those who score relatively low on abstract rape myth scales can express prejudicial beliefs when deliberating in a concrete case. ${ }^{54}$

The Review examined this evidence ${ }^{55}$ and concluded that it is compelling. ${ }^{56}$ Mandatory jury directions targeting some rape myths are already given in Scotland, ${ }^{57}$ but the Review recommended that an expanded range of myths be targeted ${ }^{58}$ and the format in which information is provided be reviewed, with consideration being given to the use of a pre-trial video, as is being piloted in England and Wales. ${ }^{59}$

\section{A pilot of judge only trials}

The measures outlined above are recommended on the assumption that the new specialist court will involve juries making determinations of guilt. The most radical of the Review's recommendations, however, is that consideration "should be given to developing a time-limited pilot of single judge rape trials to ascertain their effectiveness". ${ }^{60}$ The Review recognised this would be "controversial and

\footnotetext{
${ }^{49}$ For an explanation of the main rape myths, see F Leverick, "What do we know about rape myths and juror decision making?" (2020) 24 International Journal of Evidence and Proof 255 at 257.

50 Mock jurors are members of the public recruited to act as jurors in (often highly realistic) case simulations.

51 These are validated instruments for measuring the extent to which a person accepts rape myths. The most commonly used are the Illinois Rape Myth Acceptance Scale (IRMAS), Acceptance of Modern Myths About Sexual Aggression Scale (AMMSA) and Subtle Rape Myth Acceptance Scale (SRMAS): see Leverick (n 49) at 256-258 for discussion.

52 Leverick (n 49) at 263 (and table 2).

${ }^{53}$ In the Scottish context, see J Chalmers, F Leverick and V Munro, "The provenance of what is proven exploring (mock) jury deliberation in Scottish rape trials" (2021) 48 Journal of Law and Society 226.

${ }^{54}$ L Ellison and V Munro, "A stranger in the bushes or an elephant in the room? Critical reflections upon received rape myth wisdom in the context of a mock jury study" (2010) 13 New Criminal Law Review 781 at 790, 794-795; A M Zidenberg et al, "Lost in translation: a quantitative and qualitative comparison of rape myth acceptance" (2021) Psychology, Crime \& Law, online first publication. It has been suggested that jurors at court do not hold the same beliefs as jurors who take part in simulation studies: C Thomas, "The 21st century jury: contempt, bias and the impact of jury service" [2020] Crim LR 987 at 1004. This claim is unconvincing: see J Chalmers, F Leverick and V E Munro, "Why the jury is, and should still be, out on rape deliberation" [2021] Crim LR, forthcoming.

${ }^{55}$ Review, paras 5.18-5.20, 5.31-5.36 and 5.37-5.44

${ }^{56}$ Review, para 5.54.

${ }^{57}$ Abusive Behaviour and Sexual Harm (Scotland) Act 2016 s 6 (delayed reporting and absence of evidence of physical force).

${ }^{58}$ That a genuine rape victim will always show emotion in the aftermath or on giving evidence and that false accusations are commonly made: Review, para 5.56

${ }^{59}$ Review, para 5.44 .

${ }^{60}$ Review, para 5.70 .
} 
unpopular with many people"61 and indeed was unable to make a unanimous recommendation, with "views being fairly evenly split between retaining and dispensing with a jury" ${ }^{62}$ But the Review did not reach its conclusion lightly - it gave full consideration to the arguments in favour of juries, such as their life experience and the "democratic benefit of community involvement" ${ }^{63}$ Against this, however, the Review argued that the evidence that jurors are influenced by rape myths "cannot be left unexamined and ignored". 64

It might be countered, of course, that judges are equally prone to the influence of rape myths. Two points might be made in response. First, unlike juries, judges have to give reasons for their decisions. ${ }^{65}$ The difference this makes can be seen in two civil cases where claims for damages for sexual assault were brought. These were heard by a judge sitting alone and, in both instances, detailed and thoroughly reasoned judgments were issued. ${ }^{66}$ Secondly, false beliefs are more easily addressed. Judges are a relatively small and easily identified body - even more so given that the specialist court will be presided over by a small pool of judges - who can be educated over time.

Any encroachment on the use of jury trials has tended to meet with resistance among at least some sectors of the legal profession - an initial proposal to use judge only trials to clear the backlog of cases caused by the COVID pandemic was short-lived. ${ }^{67}$ Such resistance has already materialised in response to the Review's proposal. ${ }^{68}$ It is perplexing, however, as to why jury trial is regarded in some quarters as sacrosanct. As the Review stated, "the concept of a fair trial does not hinge on involvement of a jury". ${ }^{69}$ We do not use juries in summary cases and the number of cases prosecuted under summary procedure in Scotland vastly outweighs the number prosecuted under solemn procedure. ${ }^{70}$ Clearly summary cases do not have the same weighty consequences for the accused, but sheriff summary trials can still result in up to 12 months' imprisonment. ${ }^{71}$ Indeed, there are many jurisdictions around the world, including those bound by the European Convention on Human Rights, that do not have lay participation in criminal cases at all. ${ }^{72}$

\section{CONCLUSION}

The Dorrian Review is, at the time of writing, being considered by the Lord Justice-General, Lord Carloway. Some of its recommendations - most notably the pilot of judge only trials, but also those relating to the specialist court, pre-recorded evidence and ILR for complainers - are bold and go

\footnotetext{
${ }^{61}$ Review, para 5.1.

62 Review, para 5.3.

63 Review, para 5.2.

${ }^{64}$ Review, para 5.52.

${ }^{65}$ Review, para 5.10. The idea that juries might give reasons for their decisions was rejected by the Review as impractical - see para 5.27 .

${ }^{66}$ C V G [2017] CSOH 5 (346 paragraphs); AR v Coxon 2018 SLT (Sh Ct) 335 (207 paragraphs).

67 See Covid-19 and Solemn Criminal trials: Scottish Government Consultation Document, 13 April 2020, option seven (judge only trials) at 14. A week later, the Scottish Government confirmed it would not be pursuing this option: see Coronavirus (COVID-19) update: Cabinet Secretary for Justice statement 21 April 2020.

${ }^{68}$ See e.g. G Sweeney, "We need more juries, not fewer", Scottish Legal News, 22 March 2021.

${ }^{69}$ Review, para 5.22 .

${ }^{70}$ In 2018-19, 94\% of convictions were under summary procedure: Scottish Government (n 4) table 3. Famously, the trial of Abdelbaset Al Megrahi for murder in relation to the Lockerbie bombing also took place without a jury: see Al Megrahi v HM Advocate [2020] HCJAC 39 at [8].

${ }^{71}$ Criminal Procedure (Scotland) Act 1995 s 5(2)(d).

72 E.g. the Netherlands and South Africa: see E J Leib, "A comparison of criminal jury decision rules in democratic countries" (2008) 5 Ohio State Journal of Criminal Law 629 at 631-632.
} 
beyond the recommendations of the equivalent review in Northern Ireland. ${ }^{73}$ But Lord Carloway has not shied away from radical changes in the past. He recommended the abolition of the corroboration requirement ${ }^{74}$ and drove the adoption of taking the evidence of vulnerable witnesses pre-trial. ${ }^{75}$

It is worth returning to the driving forces behind the Review - improving the experience of complainers and tackling low conviction rates. Even if the pilot of judge only trials never materialises, the Review's other recommendations should go some way to addressing the re-traumatisation of complainers. In terms of improving conviction rates, one member of the review group rejected the proposal for judge only courts on the basis that its sole purpose would be to secure more convictions and that this is inappropriate. ${ }^{76}$ But one notable thing about the Review is that it is upfront about the fact that improving conviction rates in sexual offence cases is an aim. ${ }^{77}$

The figures set out at the start of this article support this focus. It is not acceptable that only around six per cent of reported rapes result in conviction, especially when there is evidence that a substantial proportion of incidents go unreported. If the aim was solely to improve conviction rates, in some sort of bureaucratic sense, then that would clearly be improper. But it is not. It is about securing convictions in cases where the evidence supports a conclusion that it is beyond reasonable doubt that the accused committed the offence. The Review noted informal discussions with members of the judiciary who regularly preside over jury trials in sexual offence cases. These judges reported acquittals being returned "even in cases with ample evidence of high quality" where it was "difficult to understand the rationale" for this. ${ }^{78}$

In short, the evidence of rape myths influencing jury decision making is overwhelming. It may be that this can be tacked by measures short of judge only trials. But, as the Review concluded, if these measures are not effective, "Parliament may have to decide whether it is acceptable that such a high proportion of trials for rape end in acquittal, given the nature of the crime which represents the most profound invasion of personal autonomy". ${ }^{79}$

Fiona Leverick University of Glasgow

\footnotetext{
${ }^{73}$ The Gillen Review (n 3) made similar recommendations in respect of pre-recorded evidence (at 155) and ILR (at 187) and recommended the introduction of a pre-trial video on rape myths (at 215). It stopped short of a specialist court and judge only trials. The End-to-End Rape Review (n 3) made no substantive recommendations relating to the trial process, instead asking the Law Commission to review the way that rape myths are tackled (at 17).

${ }^{74}$ Carloway Review, Report and Recommendations (2011) para 7.2.55.

${ }^{75} \mathrm{He}$ initiated and led the SCTS Evidence and Procedure Review that resulted in this change: Scottish Court Service (n 28) paras 1.2-1.4.

${ }^{76}$ Review, para 5.4.

${ }^{77}$ Review, para 5.5.

${ }^{78}$ Review, para 5.7.

${ }^{79}$ Review, para 5.70.
} 